\title{
Association of Clinical Pathologists: 73rd general meeting
}

The 73rd general meeting of the Association of Clinical Pathologists was held at Imperial College, London, from 1 to 3 October 1964. The foundation lecture was given by Professor R. J. V. Pulvertaft on 'The study of living cells in the diagnosis of malignant disease in Nigeria', and the Presidential address by Dr. Arthur Jordan on 'The development of chemical pathology'. The joint A.C.B./A.C.P. meeting was devoted to a symposium on neurochemistry. Summaries of the scientific papers follow.

RENAL MEDULLARY CYSTIC DISEASE ('MEDULLARY SPONGE KIDNEY')

N. G. SANERKIN and D. M. D. EVANS (Cardiff) Two cases of 'medullary sponge kidney' were described, one of them following nephrectomy for intractable haematuria, the other found incidentally at necropsy. In the nephrectomy case, tubular cystic change at the tips of the renal papillae led to the formation of polypi projecting into the calyces and producing filling defects in retrograde pyelograms. Such a filling defect, coupled with the haematuria, could lead to an erroneous clinical diagnosis of neoplasia.

'Medullary sponge kidney' is a rare condition due to cystic dilatation of the collecting tubules. Complications include the development of microliths within the medullary cysts and the supervention of secondary renal infection. The commonest symptom is haematuria, followed by symptoms referable to lithiasis and infection. Diagnosis is usually established by excretory urography. The condition is believed to be a congenital anomaly and Osathanondh and Potter (1964) have shown in their microdissection studies that it may be due principally to a hyperplasia of the collecting tubules.

\section{REFERENCE}

Osathanondh, V. and Potter, E L., (1964). Arch. Path., 77, 459.

BENIGN LYMPHOEPITHELIAL SALIVARY LESION OF GODWIN

A. H. CRUICKSHANK (Liverpool) In a collection of 11 cases, the benign lymphoepithelial lesion presented clinically in every case as a tumour of a salivary gland. In eight cases the parotid was affected, in two a palatal salivary gland, and in one the submandibular gland was affected. Six of the patients were female and five male; the youngest was a boy of 16 and the oldest a woman of 75 . The swellings ranged from $1 \mathrm{~cm}$. in diameter to $5 \mathrm{~cm}$. in diameter and one formed a cyst that ruptured while the tumour was being excised. Microscopic cysts lined by epithelium were present in three cases, and in one case formed an abscess that ruptured two weeks before operation leaving a small sinus in the skin. The lesion consisted of a mixture of lymphoid and epithelial components and, although the appearances in several cases suggested lymphosarcoma or reticulosarcoma, the arrangement of the epithelial component in characteristic islands (epi-myoepithelial islands) indicated the benign nature of the lesion. In one case incomplete excision of a lesion of the palate was followed by a recurrence that was cured by a radium mould.

The microscopical appearances of the benign lymphoepithelial lesion were identical with those of the salivary lesions of Sjögren's syndrome, but in all the cases the lesion was an isolated one and the sicca syndrome was absent.

\section{THE ARNOLD-CHIARI MALFORMATION}

BRIAN PEACH (Bradford) The anatomical features of 20 cases of the Arnold-Cniari malformation were presented. It was shown that the malformation is associated with a variety of anomalies involving the entire central nervous system. Commonest of these was spina bifida, usually taking the form of a myelocele or meningomyelocele, and involving vertebrae above the second lumbar level. In only one case was the spina bifida confined to segments below this level. One other case was exceptional in that no spina bifida was present. Hydrocephalus was equally common and was due to a variety of lesions: aqueductal anomalies; plugging of the foramen magnum by the malformation; blockage of the exit foramina of the fourth ventricle; blockage at tentorial level by an upward herniation of the cerebellum. Other abnormalities found were hydromyelia, diastematomyelia, cystic expansion of the fourth ventricle, beaking of the tectum, thickening of the interthalamic connexus, hypoplasia of the falx cerebri and tentorium, and microgyria.

Histological studies of the malformation showed complete demyelination or amyelination of the cerebellar component together with a reduction in the cellularity of the granular layer with abortive folia formation. Heterotopic folia were present within the cerebellar white matter in relation to the fourth ventricle.

It was concluded that the Arnold-Chiari malformation was merely one feature of a complex dysgenetic state involving the whole central nervous system. As such its morphogenesis was attributable to a fault in development occurring very early in the genesis of the nervous system. 


\section{BENIGN TUMOURS OF THE LUNG}

I. G. WILliams (Woolwich) For the 10 years from April 1953 to May 1964, 2,723 consecutive patients were operated on in the South East Regional Thoracic Unit for suspected carcinoma, from whom histological material was taken and 89 benign tumours were diagnosed; of these, 37 were hamartomas, 34 adenomas, seven chondromata, four endobronchial fibromas and one endobronchial lipoma, with five histiocytomata, and four vascular tumours.

The circumscribed hamartoma, with its abnormal mixing of normal components, occurred most frequently, usually peripheral, twice as commonly in men as in women, symptomless and found incidentally on chest radiographs.

Nintey per cent of the adenomata were of carcinoid, the remainder of cylindromatous, type. Two of the carcinoids showed the serotonin (carcinoid) syndrome, one of which had metastasized to the liver. One carcinoid adenoma was malignant $a b$ initio with lymph node extension and later liver metastasis. Two carcinoids had a coincidental squamous-celled carcinoma in another bronchus. Nevertheless the majority, including the cylindromata, showed no tendency to further aggression.

The intrabronchial mesodermal tumours (seven chondromata, four fibromas, and one lipoma) showed the characteristics of their type, producing bronchial obstruction with repeated bouts of pulmonary infection.

The only intraparenchymal mesodermal tumour which occurs with any degree of frequency is the histiocytoma; five cases were discussed, three of which presented as a radio-opacity in the lung fields. The clinical and microscopic appearances were discussed and evidence adduced as to their inflammatory nature, the characteristic cell being the histiocyte, which is excited by tissue necrosis and haemorrhage, later undergoing progressive differentiation to fibroblasts with elaboration of collagen.

Four haemangiomata resulted from a persistence of foetal and anastomotic capillaries with an arteriovenous shunt, two of which formed part of a generalized disorder of hereditary telangiectasis (Osler-Rendue Weber disease) and two capillary haemangiomata.

RAPID DIAGNOSIS OF VIRUS INFECTIONS BY IMMUNOFLUORESCENT TECHNIQUES APPLIED TO BLOOD LEUCOCYTES

R. G. SOMMERVILle (Glasgow) and P. S. MACFARLANE (Stirling) The application of fluorescent antibody techniques to pathological secretions fixed on a glass slide, or after a short pre-incubation in fertile eggs or animals with subsequent fixation and staining on a slide, offers scope for the rapid diagnosis of virus infections in established cases.

A development was described in which pathogenic viruses (all coxsackie B strains, many coxsackie As, and many adenoviruses) can be identified within peripheral blood leucocytes during the earliest stages of infection. In this technique hyperimmune antiviral serum is applied to fixed, concentrated preparations of peripheral blood leucocytes and is followed by staining with fluoresceincoupled species antiglobulin.
The implications were discussed and the possible importance for rapid epidemiological screening by non specialized peripheral laboratories was emphasized.

MYCOBACTERIUM FORTUITUM IN ABSCESSES OF MAN A. BECK (Paddington General Hospital, London) $M y c \stackrel{\bar{\omega}}{\frac{\omega}{\sigma}}$ bacterium fortuitum was isolated from three patients wh尺 had developed subcutaneous abscesses following inject tions. Two of these had been inoculated with B.C.G., the third one had iron injections. The cultural and physiological characteristics of the organisms isolated from pus agreed closely with the description of Myco. fortuitum io Gordon and Smith's (1955) taxonomic scheme of mycas bacteria. They were resistant to I.N.H., streptomycin, P.A.S., cycloserine, and, with one exception, to ethionso amide. They were avirulent for guinea-pigs but highly virulent for mice when injected intravenously. A number of mice developed spinning disease. The most conspicuous anatomical lesions were abscesses of the kidney an 9 suppuration of the labyrinth. It is thought that infection with this organism arose either from contamination of syringes or from contamination of the patient's skin.

\section{REFERENCE}

Gordon, R. E., and Smith, M. M. (1955). J. Bact., 69, 502.

ANAEMIA AND DYSPHAGIA IN A SOUTH WALES COMMUNIT

A. JACOBS and P. C. ELWOOD (Cardiff) A survey of the population aged $40-75$ years in the Rhondda Fach showe that $1.1 \%$ of men and $5.0 \%$ of women suffered from dysphagia in the post-cricoid region. Post-cricoid webs were present in $0.7 \%$ of the women but in none of the men examined.

In women comparison with a matched control grou showed that those with dysphagia alone or with we did not have an increased prevalence of anaemia of latent iron deficiency. In women with webs there was some reduction in serum pepsinogen levels and af increased incidence of parietal cell antibodies.

Although dysphagia of the Paterson-Kelly type is a important problem in middle-aged women there is no evidence in this study of the existence of a syndrome the general population in which this is associated wit anaemia. It is unlikely that iron-deficiency anaemia is aetiological factor in this type of dysphagia and in common occurrence in hospital patients may be due to selection from the population as a whole.

A CirCulating ANTICOAGULANT SPECIFICALLY ACTIVE AGAINST ANTIHAEMOPHILIC GLOBULIN

P. H. PINKERTON (Western Infirmary, Glasgow) otherwise healthy 70-year-old woman presented wit extensive spontaneous bruising. The platelet count was normal, clotting time 55 min., protmbhroin consumptiog index $140 \%$, and the thromboplastin generation tes showed a plasma defect. Assay revealed no detectabie antihaemophilic globulin (A.H.G.) activity, and inhibition of A.H.G. in normal plasma, by the patient's plasma, was 
demonstrated. Inhibitor was not present in the patient's serum.

The inhibitor was not contained in the gamma globulin fraction of plasma, and precipitin tests in agar gel against Cohn's fraction 1 were negative. Immunoelectrophoretic studies with patient's and normal plasma and Cohn's fraction 1 did not produce evidence to support an immunz aetiology. Tests for antinuclear factor, L.E. cells, and gastric antibodies were negative, as were the Coombs test and the Rose-Waaler test.

Treatment with prednisolone $40 \mathrm{mg}$. per day was followed by a rise in the A.H.G. concentration to $18 \%$. Reduction of the dose to $10 \mathrm{mg}$. per day was followed by a fall to $9 \%$, but after six months' therapy the A.H.G. concentration was $105 \%$. A favourable response to steroids is unusual in cases of this nature, but our experience should encourage a trial of this therapy.

PLASMA VISCOSITY AND OTHER BLOOD TESTS IN CORONARY THROMBOSIS

JOHN HARKNESS A battery of 11 tests was applied at frequent intervals to about 100 patients suffering from coronary thrombosis with myocardial infarction. This investigation was undertaken because of previous difficulty in correlating random laboratory tests with the clinical picture.

The two similar but distinct patterns of laboratory results followed by the majority of patients were described.

Patterns deviating from these could best be explained on the basis that an infarction could occur accompanied by no or by a few minor symptoms, to be followed after hours or days by the classical acute precordial and radiating pains. Such patients were the source of the original difficulties in correlating laboratory and clinical findings.

The level of the serum albumin usually falls for about 10 days and then rises to regain its starting value. The prognostic significance of serum albumin changes was stressed, especially where the serum albumin fails to make its expected rise.

RAISED PLASMA VISCOSITY IN THE MENTALLY SUBNORMAL AND IN DOWN'S SYNDROME

R. D. EASTHAM (Frenchay Hospital, Bristol), J. JANCAR (Stoke Park and Hortham-Brentry Groups of Hospitals), and E. H. L. DUNCAN (Department of Public Health, Bristol University) Using a Harkness viscometer, plasma viscosity readings were made on blood samples from 115 patients with Down's syndrome and from 632 patients who were mentally defective, living in the same institutions. It was found that in these patients, who were apparently clinically physically fit, there was an unexpected incidence in raised plasma viscosity values. The increased plasma viscosity values showed a significant direct correlation with the age of the patient in the mentally defective group, and both abnormal groups had plasma viscosity values significantly higher than those of a normal control group.

Variation in plasma viscosity values in the mentally defective patients after a three-month period was used as evidence of repeated undetected infections occurring in patients too subnormal to be able to communicate their sensations of illness. From the findings it was suggested that the increased level of gamma globulin known to be found in many patients with Down's syndrome was a florid but normal response to infection, or response to repeated attacks of infection, rather than production of an abnormal protein unique to Down's syndrome.

\section{PLATELET FACTOR 3 ACTIVITY IN PLASMA AND SERUM}

P. WOLF (Lewisham Hospital and the Department of Experimental Pathology, University of Birmingham) Platelet factor 3 or incomplete thromboplastin is particulate matter originating from platelets. Its presence in plasma and serum, free from platelets, accounted for the finding that plasma rendered platelet free still clots on recalcification and that $\mathrm{Al}(\mathrm{OH})_{3}$-absorbed normal serum still retains thromboplastic properties.

Platelet factor 3 particles have a specific gravity ranging from 1.02 to 1.025 and contain approximately twice as much lipid as intact platelets; it is this low specific gravity which prevents complete separation of platelet factor 3 from undiluted serum and plasma by centrifugation. To effect its complete deposition 1 part of plasma or serum was diluted with 2 parts of $0.85 \%$ $\mathrm{NaCl}$ solution and centrifuged at $173,000 \mathrm{~g}$ for one and a half hours. The supernatant dilute serum after $\mathrm{Al}(\mathrm{OH})_{3}$ absorption was now devoid of all thromboplastic activity. The dilute supernatant plasma was incoagulable on recalcification, but its coagulability was restored by addition of a saline suspension of the deposited platelet factor 3 , by platelets, or by platelet substitutes. Using diluted, platelet-factor-3-free normal plasma as substrate for estimating platelet factor 3, the following observations were made. Hougie's (1955) activation of platelets in citrate plasma and O'Brien's (1955) platelet-like activity of serum were quantitatively correlated with free particulate platelet factor 3. Platelet activation in citrate plasma did not require glass contact. There was very little platelet activation in sequestrene blood. The plasma of three patients during thrombotic episodes showed abnormally high platelet factor 3 activity.

\section{REFERENCES}

Hougie, C. (1955). Brit. J. Haemat., 1, 213.

O'Brien, J. R. (1955). Ibid., 1, 223.

HEREDITARY HEINZ BODY ANAEMIA, THROMBOCYTOPENIA, AND HAEMOGLOBINOPATHY (? Hb KOLN) IN A GLASGOW FAMILY

H. E. HUtChison, P. H. PINKerton, and A. S. DOUglas (Glasgow) found an abnormal haemoglobin component (? Hb Koln) in 10 members of three generations of a Glasgow family of remote German ancestry. In starch gel electrophoresis at $p \mathrm{H} \mathrm{8.6}$ the abnormal component moved more slowly than $\mathrm{Hb}$ A. Possession of this haemoglobin variant, which formed approximately $10 \%$ of the total, resulted in haemolytic anaemia, e.g., $51_{\mathrm{Cr}}$ $\mathrm{T} \frac{1}{2} 9$ days, and thrombocytopenia which, in one instance, resulted in a haemorrhagic state necessitating admission to hospital. A feature of the abnormal haemoglobin was 
its instability, resulting in ready development of methaemoglobin in abnormally high concentration (e.g., $18 \%)$ after 18 hours' simple incubation at $37^{\circ} \mathrm{C}$.; the incubated red cells then showed Heinz bodies in large numbers. Another evidence of the instability of this haemoglobin variant was its precipitation in the heat test (Dacie, Grimes, Meisler, Steingold, Hemsted, Beaven, and White, 1964). The clinical and laboratory findings in the family were described.

\section{REFERENCE}

Dacie, J. V., Grimes, Meisler, A., Steingold, L., Hemsted, E. H., Beaven, G. H., and White, J. C. (1964). Brit. J. Haemat.. 10, 388.

OBSERVATIONS ON AN ABNORMAL HAEMOGLOBIN ASSOCIATED WITH HAEMOLYTIC ANAEMIA

H. E. HUTCHISON (Western Infirmary, Glasgow) and H. LEHMANN and D. BEALE (Medical Research Council Abnormal Haemoglobin Research Unit, Department of Biochemistry, Cambridge) A haemoglobin was observed in a Glasgow family, which was associated with haemolytic anaemia, although it was present together with haemoglobin A and formed only a small proportion of the total haemoglobin. As the small fraction found in the affected members of this family resembled in some aspects haemoglobin Lepore, peptide chromatograms were prepared according to Ingram (1958) and Baglioni (1961) of this haemoglobin, haemoglobin $A_{2}$, and haemoglobin A. Haemoglobin Lepore contains part of the $\delta$-chain (see Huisman, 1963) of haemoglobin $A_{2}\left(\alpha_{2} \delta_{2}\right)$. The peptide chromatograms of the present abnormal haemoglobin showed peptides typical of haemoglobin $A$, and none of these characteristic of haemoglobin $A_{2}$ or of haemoglobin Lepore. The ultraviolet spectrum and the peptide chromatogram also showed none of the features of haemoglobin F. Hence we considered the new haemoglobin to be a variant of haemoglobin A.

Itano and Robinson's (1959) hybridization with canine haemoglobin (according to Huehns, Shooter, and Beaven, 1962) demonstrated that the abnormality in the haemoglobin under investigation was in the $\beta$-chain.

On prolonged digestion with trypsin (Armour Pharmaceutical Co. Ltd.) we regularly obtained an additional histidine-containing peptide in the 'finger print'. This particular trypsin contains some chymotrypsin and the peptide comes from the 'core' of the haemoglobin molecule, which is that part which usually remains insoluble after tryptic digestion according to Ingram (1958) and Baglioni (1961). It is therefore possible to place the abnormality as somewhere between residues 83 to 120 of the 146 constituting the $\beta$-chain.

At this time we began to investigate a sample of haemoglobin Köln kindly sent to us by Professor W. Pribilla. Haemoglobin Köln turned out to be identical in every respect with the haemoglobin of the Glasgow family, which incidentally has German ancestry. The electrophoretic properties were the same, the abnormality could be localized within the $\beta$-chain, and lastly the fingerprint showed the same histidine-containing abnormal core-peptide as the haemoglobin from the Glasgow family. We conclude therefore that the haemoglobin found in the Glasgow family is haemoglobin Köln.

\section{REFERENCES}

Baglioni, C. (1961). Biochim. biophys. Acta (Amst.), 48, 392.

Huehns, E. R., Shooter, E. M., and Beaven, G. H. (1962). J. mole Biol., 4, 323.

Huisman, T. H. J. (1963). Advance clinical Chem., 6, 231.

Ingram, V. M. (1958). Biochim. biophys. Acta (Amst.), 28, 539.

Itano, H. A., and Robinson, E. (1959). Nature (Lond.), 184, 1468.

Pribilla, W. (1962). In Haemoglobin Colloquium, edited by H. Lehman and K. Betke, p. 73. Thieme, Stuttgart.

The following are synopses of papers delivered b $\overrightarrow{0}$ speakers at the joint A.C.P./A.C.B. meeting.

HISTOCHEMISTRY OF THE CENTRAL NERVOUS SYSTEM

C. w. M. ADAMS (Department of Pathology, Guy' $\overrightarrow{\Im^{\circ}}$ Hospital Medical School, London) Histochemistry provides the most accurate method for the histological localization of substances, substrates, and enzymes. Unti recently it has suffered from the drawback that it has been essentially non-quantitative. However, recent emphasis on quantitative histochemistry and cytos chemistry is closing the gap between what is known as 'slide' histochemistry and 'test-tube' histochemistry. Thiฏ paper, however, is devoted to illustrating some examples of the applicability and use of 'slide' histochemistry inge neurological research.

The histochemical localization of lipids in the myelin sheath is illustrated by specific methods for cholesterol, trio glyceride/cholesterol esters, phosphoglycerides, sphingos myelin, cerebroside, and plasmalogen phospholipids. The use of these methods is also illustrated for identifying lipid changes in demyelinating disorders and lipid storage diseases. Finer localization of lipids may in future be obtained by adapting histochemical techniques tơ electron microscopy, but such methods are at presen? still undeveloped.

Histochemical enzyme methods are being fairly. extensively employed in research on the nervous systemo Acetylcholinesterase activity may be readily displayed in various components of the nervous system, such as parasympathetic ganglia, certain axons, and the neuro muscular junction. A use of this method is illustrated foe displaying the altered parasynpathetic innervation in achalasia of the cardia and Hirschsprung's disease. 을

The histochemical tetrazolium methods for dehydro genases and nucleotide reductases (diaphorases) are nowe being frequently applied to studies of neuronal and neuro $\overline{\bar{N}}$ glial disorders, cerebrovascular disease, nerve degeneraos tion, muscle disease, and tumour pathology. A use of such dehydrogenase methods is exemplified here bP illustrations of the changes in oligodendroglial oxidatives activity in multiple sclerosis and experimental cyanide demyelination.

EFFECT OF CERTAIN NEUROTOXIC SUBSTANCES ON INTER MEDIARY METABOLISM IN BRAIN

JILL E. CREMER (Toxicology Unit, Medical Researci Council Laboratories, Carshalton, Surrey) The effect of two neurotoxic agents, triethyl-tin and triethyl-leade 
were studied. Although chemically they are very similar each compound brought about quite different signs of poisoning when given to rats; triethyl-tin had a depressant action and also produced a characteristic oedematous lesion in the white matter of the brain and spinal cord. Rats receiving triethyl-lead became excitable; often they had continuous tremors throughout the body but no oedema occurred in the central nervous system.

The addition in vitro of either organo-metal compound to brain slices led to identical effects on the metabolism of [U-C $\left.{ }^{14}\right]$ glucose. Its oxidation was inhibited, there was an alteration in the levels of free amino-acids within the slice, and a reduction in the rate at which glucose carbon was found in $\gamma$ aminobutyric acid, glutamine, aspartic, and glutamic acids. Brain slices prepared from animals previously injected with either triethyl-tin and triethyllead were unable to metabolize glucose in a normal manner. Differences between the two groups may have reflected the different clinical states of the animals at the time of removing the brains. The levels and radioactivity of amino-acids in whole brain in situ were measured in rats injected intravenously with [U-C $\left.{ }^{14}\right]$ glucose. There was good agreement between the values obtained in vivo and in vitro for the control animals but not for animals which had received either triethyl-tin or triethyl-lead. Time-course curves for radioactivity in the serum and brain after giving [U-C ${ }^{\mathbf{1 4}}$ ] glucose intravenously were obtained. Differences from the control animals indicated that both neurotoxic agents interfere with glucose metabolism in vivo but no quantitative values can as yet be given. It is hoped that further work will help to provide answers to the following questions: (1) How much glucose is used by a rat's brain in vivo? (2) Is this value altered by certain neurotoxic agents? (3) What controls the passage of glucose from the blood to the brain?

\section{RECENT WORK IN THE BIOCHEMISTRY OF MULTIPLE SCLEROSIS}

R. H. S. THOMPSON and G. R. WEBSTER (Department of Chemical Pathology, Guy's Hospital Medical School, London) Two biochemical approaches to the problem of multiple sclerosis which are being actively studied at the present time were briefly reviewed. First, recent work on the production of experimental allergic encephalomyelitis in animals was considered since this condition is regarded by some workers as constituting a model for the human disease, which may represent an allergic response to some endogenously produced antigen. The work of Field in Newcastle and of Lumsden in Leeds and their colleagues on the isolation of active encephalitogenic fractions from human and animal nervous tissue was described and the possible relationship of the work to the pathogenesis of human multiple sclerosis was discussed.

Work at Guy's Hospital on certain aspects of phospholipid biochemistry in the nervous system has shown the presence in brain of a number of enzymes concerned with the metabolism of long-chain fatty acids and of potentially cytolytic lysophosphatides. The question whether some abnormality in these enzyme systems could play a part in the processes of myelin degeneration is still being studied. Recent work in this field has also shown that the proportion of certain polyunsaturated long-chain fatty acids in the serum of patients with multiple sclerosis are reduced and that there appears to be a correlation between the extent of the reduction and clinical activity of the disease. Further work is being carried out to elucidate the cause and possible significance of this finding.

\section{BIOCHEMISTRY OF THE LIPIDOSES}

J. N. CUmINGS (National Hospital, Queen Square, London) The lipid composition of the adult brain was described, together with an indication of which of these substances were present in myelin and in nerve cells. Changes take place during myelination but little metabolic alteration occurs once a lipid compound is laid down.

The biochemical features of sphingomyelin, cerebroside, sulphatide, ganglioside, and lecithin were given in brief.

The patients with the various forms of lipidoses seen over the past 12 years numbered 125 and a list was shown. The major biochemical features as demonstrated by thin-layer chromatography of a number of these conditions were given. In Niemann-Pick's disease there was an increase of sphingomyelin in the brains of four cases, while in Gaucher's disease there was an increase in cerebroside. The white matter of the brain in metachromatic leucodystrophy ( 31 had been examined) showed a well-marked increase in sulphatide. Ganglioside increases were demonstrated in six cases of Tay Sachs' disease where there was a fast band containing $80 \%$ N.A.N.A. as compared with $5 \%$ or less in a normal cerebral cortex. In eight cases of gargoylism there was an additional even faster band containing N.A.N.A. but not hexosamine. All these features are of absolute diagnostic value.

\section{BIOCHEMISTRY OF MUSCULAR DYSTROPHY}

R. J. PENNINGTON (Department of Clinical Biochemistry, University of Newcastle-upon-Tyne) In human dystrophic muscle many enzyme activities are decreased and some are increased. The changes so far observed are probably all secondary to the non-specific muscle degeneration. The muscle lactate dehydrogenase isoenzyme pattern is altered and resembles that of foetal muscle; this happens also in other muscle diseases. The proportions of individual myoglobins are abnormal and also resemble the pattern seen in foetal muscle. Dystrophic muscle contains less potassium and more sodium than normal.

The creatinuria found in muscle diseases is probably secondary to loss of muscle, although there is some evidence that in muscular dystrophy the muscles may also lose creatine more readily. An amino-aciduria has been frequently reported, but no specific amino-acid is implicated. Many constituents of plasma show significant changes, including an increase in $\alpha_{2}$-globulin. Serum magnesium shows an abnormally high binding. At least nine serum enzymes are elevated in Duchenne type dystrophy. Creatine kinase is the most sensitive and specific for diagnosis and values up to 400 times normal 
have been recorded. High values are probably present from birth in at least some cases of Duchenne dystrophy. The majority of female carriers of this type of dystrophy have raised serum creatine kinase levels, thus providing a valuable test. The leakage of muscle enzymes into the blood is not completely specific for muscular dystrophy, but does not occur to an appreciable extent in neurogenic muscle diseases. It is not justifiable to conclude, however, that muscular dystrophy is caused by a defect in the muscle cell membrane. The underlying cause is still totally unknown.

INBORN ERRORS OF METABOLISM IN RELATION TO THE CENTRAL NERVOUS SYSTEM

L. T. WOOLF (Oxford) Many inborn errors of metabolism are associated with dysfunction of the central nervous system. They include transport defects, e.g., Hartnup disease, nephrogenic diabetes insipidus, defects of the metabolism of metals, porphyrins, carbohydrates, hormones, vitamins, and purines. Absence of an enzyme catalysing an intermediary stage in the catabolism of an amino-acid frequently causes mental or neurological disease.

The gene coded for the enzyme phenylalanine hydroxylase can mutate to an inactive allele; a homozygote for the mutant allele cannot make the enzyme and suffers from phenylketonuria, a disease characterized by gross mental retardation, psychotic features, and neurological abnormalities. Absence of the enzyme prevents the normal oxidation of phenylalanine to tyrosine; from birth onwards phenylalanine accumulates in the blood and tissues, some undergoing abnormal reactions to phenylpyruvic acid, etc. The mental and neurological features result from intoxication by phenylalanine and its abnormal metabolites; giving a diet low in phenylalanine from birth produces clinically normal children and adults. The mechanism by which phenylalanine, etc., damage the brain is unclear, but there is reduced myelination, active demyelination, and inhibition of synaptic transmission. Leucinosis (maple syrup urine disease) resembles phenylketonuria but there is much more destruction of brain tissue and early death is the rule; the cause is absence of the decarboxylase(s) for the $\alpha$-keto acids corresponding to leucine, isoleucine, and valine. In histidinaemia, genetically and biochemically like phenylketonuria and leucinosis, a speech defect may be the only sign of dysfunction of the central nervous system. The slow deposition of copper in Wilson's disease causes tremor, spasticity, and psychosis rather than amentia.

TIME FACTOR RELATING PLASMA AMMONIA WITH HEPATIC COMA

J. C. B. FENTON (Department of Clinical Chemistry, University of Newcastle-upon-Tyne) In cases of liver disease the concentration of plasma ammonia is not directly related to the level of consciousness. Coma results when a high level of ammonia persists over hours or days. Conversely, a fall in plasma ammonia heralds subsequent recovery. For this reason isolated estimations of ammonia do not correlate with the immediate conscious state but rather predict the subsequent course of events. This time lag between a rise in the level of ammonia and its effect upon cerebral function is illus=trated in the following case.

A patient was admitted to hospital in hepatic pre-com旅 and at this time the plasma ammonia was found to bes $172 \mu \mathrm{g}$. per $100 \mathrm{ml}$. The ammonia level fell on treatmen with Neomycin and the patient made a good recovery? One month later the patient volunteered to take capsules of ammonium acetate and sufficient was given to raise and maintain the level of ammonia to the same value as was first found on admission.

The electroencephalograph was recorded daily and the plasma ammonia twice daily. The most marked slowing of the E.E.G. record occurred approximately 36 hour $\$ 0$ after the plasma ammonia had reached $170 \mu \mathrm{g} . / 100 \mathrm{ml}$.

STUDIES OF BLOOD AMMONIUM IN RESPIRATORY FAILURE $\frac{\vec{N}}{\mathrm{~N}}$

LORNA O. MORRIS and G. M. ABER (Birmingham) Studies of arterial ammonium concentration in patients with chronic obstructive airways disease have shown that this is often elevated during episodes of acute respiratorywa infection, returning to normal values during recovery. The possible relationship between arterial ammonium levels and arterial gas tensions and $p \mathrm{H}$ is discussed.

It has been shown that although a reduction in the arterial ammonium concentration can be produced by increasing the inspired oxygen concentration in theses patients, 'in vitro' oxygenation of blood from the same patients failed to produce any change in the ammoniump levels.

Measurements of the release of ammonium into the renal vein at different levels of arterial oxygenation have also been made.

\section{URINE CALCIUM/CREATININE RATIO IN HYPERCALCAEMIA}

M. R. WILLS (Department of Chemical Pathology, Bristop Royal Infirmary) The work reported was undertaken to investigate the validity of a random urine sample as a measure of urine calcium excretion in normal subjectsô and patients with disorders of calcium metabolism, and in particular to investigate the effect of variations ino urine concentration and hence in creatinine concentration on the calcium/creatinine ratio. As the effect of dieto cannot be disregarded all tests were made on fasting subjects, and to exclude any effect from diurnal variations $N$ the tests were performed between 0600 and 1200 hours.

After overnight urine concentration, an oral water load was given to induce diuresis and provide specimensw with a relatively wide range of creatinine concentrationo for each subject.

Two hundred and thirty-two urine specimens were collected from 26 normal subjects and in these subjectse the fasting calcium/creatinine ratio was found to be independent of the urine creatinine concentration. One hundred and twenty-two urine specimens were collected $\frac{\mathbb{D}}{\mathbb{D}}$ from 10 patients with primary hyperparathyroidism, and? 62 urine specimens from eight patients with hyper- $\mathbb{D}$ calcaemia due to other causes. In eight of the 10 patientso 
with primary hyperparathyroidism and in two of the eight with hypercalcaemia due to other causes, ratios were found to be high when the creatinine concentration was low but normal when the creatinine concentration was high.

The results suggest that negative tests for hypercalciuria should not be accepted in the interpretation of a random urine sample if the urine creatinine level is more than $40 \mathrm{mg} . / 100 \mathrm{ml}$. It may well be that measures of 24 -hour urine calcium output are similarly affected by urine concentration.

\section{MAGNESIUM AND SERUM ALKALINE PHOSPHATASE}

D. N. BARON (Royal Free Hospital, London) The KingArmstrong procedure usually used in the U.K. for assay of serum alkaline phosphatase employs phenylphosphate as substrate: Buch and Buch (1939) showed that $\mathbf{M g}^{++}$ ( $\operatorname{lmM}$ ) causes activation of this enzyme reaction by about $30 \%$, but their finding has been neglected. $\mathrm{Mg}^{++}$also causes activation with the procedures of Bodansky (glycerophosphate) and of Bessey, Lowry, and Brock (p-nitrophenyl phosphate).

We have confirmed progressive activation of serum alkaline phosphatase by $\mathbf{M g}^{++}$, reaching a plateau when the concentration of $\mathbf{M g}^{++}$in the buffer-substrate is about $0.5 \mathrm{mM}$, with the modified phenylphosphate procedures of King and Wootton (1956) (manual) and Bell and Collier (1964) (AutoAnalyzer). Activation in sera from patients with liver disease averaged $33 \%$; similar results were obtained with osteoblastic bone disease. Chelation of $\mathrm{Mg}^{++}$by E.D.T.A. progressively removed serum alkaline phosphatase activity, this being almost complete at $7.5 \mathrm{mg}$. E.D.T.A./ml. serum. It is suggested that $\mathbf{M g}^{++}$ be added, to $\operatorname{lmM}$ concentration, for all assays for serum alkaline phosphatase.

\section{REFERENCES}

Bell, J. L., and Collier, M. (1964). J. clin. Path., 17, 301. Buch, I., and Buch, H. (1939). Acta med. scand., 101, 211. King, E. J., and Wootton, I. D. P. (1956). Micro-Analysis in Medical Biochemistry, p. 83. Churchill, London.

ASSAY OF SMALL AMOUNTS OF ISOLATED LEUCOCYTES

U. OMAR-AHMAD and D. N. BARON (Royal Free Hospital, London) Leucocytes were obtained by a modification of the method of Baron and Roberts (1963). Defibrinated blood is treated with heavy dextran to produce a mixed supernatant suspension of leucocytes and erythrocytes; the latter are finally removed by lysis with water.

On extracting the leucocytes from small volumes of blood (8-15 ml.) the results for sodium and potassium showed considerable error. This was due to contamination by extracellular material which remained on the inner surface of the test tube, also as a layer over the cell mass, as well as intercellularly. Estimation by ${ }^{131} \mathrm{I}$-albumin showed that this contamination could amount to more than $50 \%$ of the wet weight of the leucocytes.

For the modified method thin tubes were made from 250 gauge polythene sheet. The leucocytes were centrifuged into its conical tip and the rest of the tube was cut away. Excess extracellular material which overlay the cell mass was blotted off. The results of analysis showed minimal contamination and gave the expected intracellular pattern for sodium and potassium.

A polythene tube has other advantages. Its light weight reduces weighing errors. When sealed all round, it minimizes loss of water by evaporation from the cell mass. It can be conveniently stored in the deep freeze, dispatched through the post for neutron activation analysis, or ashed as a whole without need for transfer of cells.

\section{REFERENCE}

Baron, D. N., and Roberts, P. M. (1963). J. Physiol. (Lond.), 165, 219.

\section{THE MEASUREMENT OF CHELATABLE BODY IRON}

J. FIELDING (Paddington General Hospital, London) The differential ferrioxamine test is a simple method for the measurement of in vivo chelation of body iron by desferrioxamine.

A single six-hour specimen of urine is obtained after intravenous Desferal, accompanied by $59 \mathrm{Fe}$-ferrioxamine. Two values are measured: Fd, the excretion of ferrioxamine derived from body iron by chelation, and Fex, the excretion of ferrioxamine from a known intravenous dose. The data enables in vivo chelation of iron (Fv) to be calculated by simple proportion.

Desferrioxamine chelation proceeds for about half an hour after injection.

The results in normal subjects, in cases with known high iron stores, and in cases of iron-deficiency anaemia were described. High, normal, and low body iron status have been differentiated.

Fv values in the higher ranges obtained in iron storage diseases and in haemolytic states, are differentiated by the pattern of excretion, high Fd values and low Fex values respectively.

The results suggest that there are two main sources of chelatable body iron: stores as ferritin-haemosiderin, and iron newly released from haem, in a more readily chelatable form.

The variable chelatability of different sources of body iron may be significant for the understanding of iron metabolism. It may explain, for instance, the preferential utilization of iron released from red cells or absorbed from the intestine, rather than storage iron, in the biosynthesis of haem.

SERUM PROTEIN-BOUND IODINE ESTIMATION IN THYROID DISORDERS

F. J. PICK ${ }^{1}$, C. SANDERSON, S. P. WARD (Stafford) and J. A. H. WATERHOUSE (Birmingham) The work carried out over the past four years at the P.B.I. Reference Laboratory at the Staffordshire General Infirmary is described together with the results of an extensive clinical survey.

The estimation of the iodine contained in thyroxine and tri-iodothyronine (serum P.B.I.) reflects the level of the circulating thyroid hormones. The method used it that of Acland (1957) and requires technical competence and care; a separate room and equipment is preferable and centralization an advantage. The test can be per- 
formed on patients of any age and state of health. Over 10,000 P.B.I. estimations have been carried out. Errors may arise from contamination of the blood by iodinecontaining preparations used for therapeutic or radiological purposes.

A survey of 600 adults gave statistically a normal range of P.B.I. of 3.7 to $7.0 \mu \mathrm{g} . / 100 \mathrm{ml}$., low values being found in hypothyroidism and high values in thyrotoxicosis. Using these P.B.I. levels as the sole criterion of diagnosis, $96.2 \%$ of normal people, $95.8 \%$ of thyrotoxic, and $100 \%$ of hypothyroid patients are correctly assessed. In practice all suspected cases of thyroid disorder with repeated P.B.I. values between 4.0 and $7.0 \mu \mathrm{g} . / 100 \mathrm{ml}$. may be regarded as normal. Values between 3.6 and 4.0 and 7.0 and $7.5 \mu \mathrm{g} . / 100 \mathrm{ml}$. are considered borderline. In borderline cases of hypothyroidism the T.S.H.-P.B.I. test is useful and similarly the tri-iodothyronine-P.B.I. test in suspected thyrotoxicosis.

The P.B.I. estimation was found to be a reliable, accurate, and inexpensive routine test in the diagnosis of thyroid disorders, particularly in the early detection of latent hypothyroidism, and of great value in following up treatment without curtailment of therapy.

\section{REFERENCES}

Acland, J. D. (1957). Biochem. J., 66, 177.

${ }^{1}$ Now at New End Hospital, London, N.W.3.

FRACTIONATION OF GASTRIC SECRETIONS BY THE GEL FILTRATION METHOD

J. SCHRAGER (Royal Albert Edward Infirmary, Wigan) Attempts have been made in our laboratory to fractionate gastric secretion by gel filtration. Preliminary work witb Sephadex G.100 resulted in effective separation of three fractions: 1 macromolecular fraction; 2 pepsin, an 3 polypeptides.

Quantitative analysis showed that the macromoleculaf fraction contains all the glucosamine, galactosamine, an fucose, $70 \%$ of the sulphate, and 40 to $50 \%$ of the $\mathrm{N}$-acetyl neurominic acid of the filtered gastric secretion It also contains all the blood group activity. None found in the second or third fractions.

The amino-acid content of the macromolecule was the $\vec{P}$ analysed on the Autotechnicon amino-acid analyser. The data obtained suggest that the protein component forms a scaffolding for the carbohydrate chains. Quantitative analysis of the carbohydrate components shows the presence of glucosamine, galactosamine, galactosero glucose, mannose, and fucose. $\mathrm{N}$-acetyl-neurominic aciej and sulphate have also been estimated.

The data obtained suggest that the gastric mucopolysaccharide is one large macromolecule consisting of \& protein core to which are attached carbohydrate side. chains. Two types of side chains are tentatively suggested. One side chain consists of glucosamine, galactosamine fucose, and sulphate. The second side chain consists of galactosamine, glucose, mannose and $\mathrm{N}$-acetyl-neur minic acid, and probably also galactose.

The ratio of side chain A to side chain B is $2: 1$. Ther is also tentative evidence that side chain $A$ is attached to the amino-acid threonine and side chain $\mathbf{B}$ to the amino acid serine. The mucopolysaccharides of patients wit duodenal ulcers appeared to be deficient in sulphate an 7 $\mathrm{N}$-acetyl-neurominic acid. 